\title{
EVALUATION OF THE EFFECT OF HYALURONIC ACID AND CHITOSAN BIOCOMPOSITE NATURAL POLYMERS IN ALVEOLAR RIDGE PRESERVATION: AN EXPERIMENTAL STUDY IN DOGS
}

\author{
Rania A. A. EI behairy*, Hoda G. H. Hammad ${ }^{* *}$, Ibrahim H. Ahmed ${ }^{* * *}$ \\ and Monazah G. Khafagi****
}

\begin{abstract}
Alveolar ridge preservation procedures became a famous procedures after tooth extraction. Different approaches and materials had been studied. Faster and new bone formation is the concept.

Objective: To evaluate the early stages of alveolar bone healing of tooth extraction sockets filled with bioactive composite (chitosan-bioactive glass) $\mathrm{CH}-\mathrm{MB}$ scaffold soaked in hyaluronic acid (HAL) in a canine model.

Materials and Methods: Six mongrel dogs were involved in this study; they were divided into two groups according to sacrifice time (three and six weeks). Each of these groups includes three animals. Animals were subjected to extraction of the third premolar bilaterally. The right extraction socket received bioactive composite (chitosan-bioactive glass) CH-MB scaffold soaked in $0.2 \%$ hyaluronic acid, while the left side had received chitosan-bioactive glass scaffold $\mathrm{CH}-\mathrm{MB}$ only. The healing extraction sockets were evaluated by (Fourier Transfer Infra-Red spectroscopy) FTIR; where three variables were studied: Matrix quality, degree of crystallinity and degree of calcifications.
\end{abstract}

Results: Hyaluronic acid (HLA) treated groups showed significant results at 6 weeks over all other groups as regard collagen content and crystal maturity. While, degree of calcification showed non-significant results. Moreover, HLA groups showed significant increase from 3 weeks to 6 weeks over non treated groups.

Conclusion: Hyaluronic acid was effective in extraction socket healing as regard collagen content at 3 and 6 weeks and crystal maturity especially at 6 weeks. While degree of calcification was negatively affected. It was postulated that HLA sustained its release on the biocomposite scaffold for 6 weeks postoperatively.

KEYWORDS: Natural polymers, FTIR Spectroscopy, ridge preservation, chitosan, melted bioactive glass, hyaluronic acid and dogs.

\footnotetext{
* Oral and Maxillofacial Surgery Department, Faculty of Oral and Dental Medicine, Badr University, Cairo, Egypt. ** Lecturer, Dental Biomaterials Department, Faculty of Dentistry, Misr University of Science and Technology (MUST), Giza, Egypt, Former.

***Surgery, Anesthesiology, and Radiology, Faculty of Veterinary medicine, Suez Canal University.

**** Spectroscopy Department, Physics Division, National Research Centre, Egypt.
} 


\section{INTRODUCTION}

Adequate alveolar bone height and width was demanded for ideal functional and esthetic reconstruction. Alveolar bone resorption after tooth extraction remains a challenge in dentistry, specially the first three months. ${ }^{1,2}$ It is a reality, there is no ideal biomaterial option. A variety biomaterials have been used as scaffolds for bone regeneration, for example bioactive ceramics, natural and synthetic polymers and their composites. Natural polymers and their composites are considered promising. Hyaluronic acid (HLA) and chitosan $(\mathrm{CH})$ are examples of natural biodegradable polymer composite ${ }^{3-5}$.

Polymers can easily be tailored for specific requirements through manipulating their chemical compositions and structures. While, bioactive glass is the best example of bioactive ceramics. ${ }^{3,4,6}$ Hyaluronic acid (HLA) is a principle component of the extra cellular matrix (ECM). In the field of oral surgery, it demonstrated anti-inflammatory, antioxidant, antibacterial properties, and offers a beneficial effect after wisdom tooth extraction surgery and meniscus repair. ${ }^{5-9}$ It is widely used for bone tissue engineering with excellent viscoelasticity, water solubility and osteogenetic properties. ${ }^{10,11}$ Subsequently, HLA treatment can save the amount of bone graft used and offers ease of use. ${ }^{10}$

HLA-based materials were applied into bone defects alone or in association to scaffolds in experimental animals. ${ }^{5}$ Osteoconductive scaffold mixed with HLA can improve the rate of bone formation by enhancing osteogenic cell adhesion, proliferation, and migration..$^{910}$ ELkarargy 2013, demonstrated that biphasic calcium phosphate (HA/ $\beta \mathrm{TCP})$ scaffold with HLA provides more osteoconductive property when compared to samples without HLA. ${ }^{5}$ The bone density and new bone formation measurements of Hyaluronic acid /biphasic calcium phosphate (HLA/HA- $\beta$ TCP) treated samples was higher by 1.7 and 1.78 times respectively, than that of the HLA free samples at 2 weeks..$^{10,12}$
In an animal study, Sasaki et al (1995) concluded the osteoinductive action of HLA at 2 weeks by accelerating new bone formation of rat femur through stimulating undifferentiated mesenchymal cells (UMC) ${ }^{13}$ Moreover, Yazan et al demonstrated HLA bone induction by stimulating (UMC) around dental implant in rabbit's mandibular molar area. ${ }^{5,14}$ HLA levels are dramatically elevated immediately after tooth extraction. It aids both soft tissue and bone healing. Exogenous HLA effect on wound healing of rat cheek defects had shown that HLA improved microcirculation ${ }^{15,16}$

Chitosan as a natural polysaccharide has the advantages being (biocompatible, antibacterial, stable, non-immunogenic and biodegradable) as well as capability of being sterilized. Chitosan improves osteogenic line differentiation of human stem cells. $\mathrm{CH}$ is mechanically weak which hinders its use alone. Chitosan biocomposites with inorganic materials result in 3D scaffolds. The most successful examples of these inorganic materials include bioactive glass. ${ }^{17}$

Typical bioactive glasses, widely studied by (Hench et al. Andersson et al.) has defects in their dissolution mechanism (glass 45S5 and glass $\mathrm{S} 53 \mathrm{P} 4)$ due to the formation of a thick silica oxide ( $\mathrm{SiO} 2)$ rich layer, which is responsible for residual unreacted glass, at the surgical site for 14-years post-surgery. New bioactive glass: 46S6 bioactive glass ( $\mathrm{SiO} 2$ glasses containing calcium $\mathrm{Ca}$ and phosphorus $\mathrm{P}$ ), has the advantage of bioactivity, and high mechanical properties. Formation of a carbonate substituted hydroxyapatite-like layer (HCA) on the bioglass surface is responsible for its bioactivity. This layer is similar to the mineral composition of bone, therefore; it bonds strongly with living bones. ${ }^{17}$

The chitosan $(\mathrm{CH})$ and melted bioactive glass biocomposite (CH/MB) showed an excellent capacity to form the apatite layer on the bioglass surface. ${ }^{18}$ Moreover, it showed rough surface compared chitosan alone. The ratio $1 \mathrm{CH}: 2 \mathrm{MB}$ 
scaffold composition revealed highest viscosity of all prepared scaffold consistencies. MB increases surface area of scaffold and bioactivity. ${ }^{17}$

Fourier transform infrared spectroscopy (FTIR) as non-invasive method that is popular for chemical characterization of mineralized tissues and natural materials, demonstrating frequencies of several vibrational modes of both organic and inorganic molecules, which are active in the infrared. The mineral phase show carbonate and phosphate spectral peaks while, bone organic phase are mainly made of type I collagen that appears as spectral bands of amide I, amide II. ${ }^{20,21}$

\section{AIM:}

The study aim was to evaluate the effect of soaking chitosan bioactive glass biocomposite scaffolds in $0.2 \%$ hyaluronic acid for fresh extraction socket of dogs.

\section{MATERIALS AND METHODS}

\section{Methods:}

\section{Experimental animals:}

The experimental study was performed at the Department of Surgery, Anesthesiology, and Radiology, Faculty of Veterinary Medicine, Suez Canal University, Egypt. Six adult healthy male mongrel dogs having comparable age (About one year), average weight $10-15 \mathrm{~kg}$, were involved in the study. Study animals were divided into two equal groups according to sacrifice time; group I: three weeks and group II: Six weeks. So; each group included three dogs.

\section{Surgical procedures:}

All experimental dogs were operated under general anesthesia (GA). Each animal was premedicated with Valpam IM (product of AMOUN Pharmaceutical Industries CO (APIC) S.A.E El Salam city, Cairo, Egypt) in a dose of $0.5 \mathrm{mg} / \mathrm{Kg}$ body weight 10-15 minutes; prior to induction anesthesia. Cannulation and injection of prophylactic antibiotic were carried out with Flumox $500 \mathrm{mg}$, 2ml IV (Egyptian International Pharmaceutical Industries CO (EIPICO) 10Th of Ramadan city, Egypt), followed by Fortecortin 2ml IM (product of GALAXCO Pharmaceutical Industries CO. El Salam city, Cairo, Egypt). Furthermore; induction anesthesia was achieved using IV administration of Sodium Thiopental IV (Egyptian International Pharmaceutical Industries CO (EIPICO) 10 th of Ramadan city, Egypt), (20-30 mg/kg body weight in dilution of $2.5 \%$ solution). General anesthesia was maintained using again IV Sodium Thiopental.

Six animals were subjected to bilateral extraction of the mandibular third premolar. Initially; crown of those teeth was hemi sectioned vertically with tungsten carbide fissure bur. Then; surgical elevators were gently applied for luxation and extraction the teeth roots without traumatizing the surrounding alveolar bone (Fig. 1: a\&b). The empty tooth socket was irrigated with saline solution. The right socket had received chitosan bioactive glass CH-MB scaffold (Chitosan :ALDRICH, medium molecular weight, Germany) /Melted bioactive glass (Sigma, Germany) in a ratio of $1 \mathrm{CH} / 2 \mathrm{MB}$ soaked in Gengigel ${ }^{\circledR}$ (Dent-O-Care Dalmeyer Road London) High-molecular weight, $0.2 \%$ hyaluronic acid (mean m/w 1,500,000) (1 ml volume) for 5 minutes; while the left side had get only a chitosan bioactive glass scaffold (Fig. 1: c). Finally; surgical releasing incisions were made for primary wound closure using 4/0 Coated VICRYL ${ }^{\circledR}$ (polyglactin 910) Suture (C Ethicon US, LLC) (Figure 1: d)). Animals divided into two groups according to sacrifice date group I (3 weeks) and group II (6 weeks).

Postoperative therapy including analgesic nonsteroidal anti-inflammatory; Cataflam $75 \mathrm{mg} / 2 \mathrm{ml}$ IM Cataflam 75mg IM (Novartis Pharma, Pharmaceutical industries Co, Cairo, Egypt)and antibiotic Flumox 500 were systemically administrated to the operated dog once a day for three successive days. 


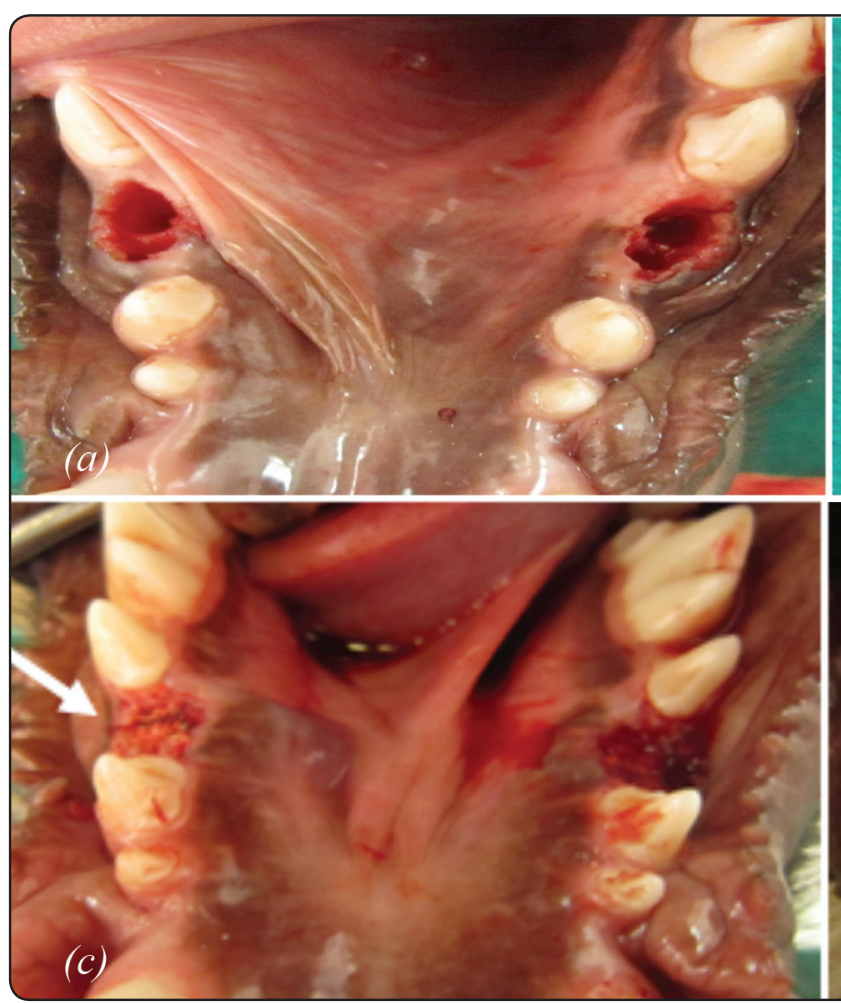

Fig.(1): Showing:

a: Sockets of extracted third premolar right and left

c: Application of pre-fabricated chitosan-bioactive d: Interrupted surgical sutures for wound closure (white arrow).

Animal sacrifice was done by rapid IV injection of overdose Sodium Thiopental at 3 weeks and 6 weeks. Mandibles was dissected, sectioned and stored in neutral formalin $10 \%$.

\section{FTIR spectroscopic analysis: Chemical quantita- tive analysis}

The studied samples were prepared and analyzed spectroscopically. Bone blocks were removed from formalin and gently washed before analysis under distilled water, then dehydrated to avoid water spectrum observation, The assessment was done for the new bone formed inside the socket and the original bone for each sample which were analyzed quantitatively by using Fourier Transform InfraRed spectrometer (FT/IR-6100, Jasco, Japan). All spectra were recorded in the range $\left(4000-400 \mathrm{~cm}^{-1}\right)$, the number of scans was 32 , and the resolution was $4 \mathrm{~cm}^{-1}$ and scan speed $2 \mathrm{~mm} / \mathrm{s}$. Spectroscopic parameters that are evaluated in the infrared spectra of bone include; collagen content,degree of hydroxy-

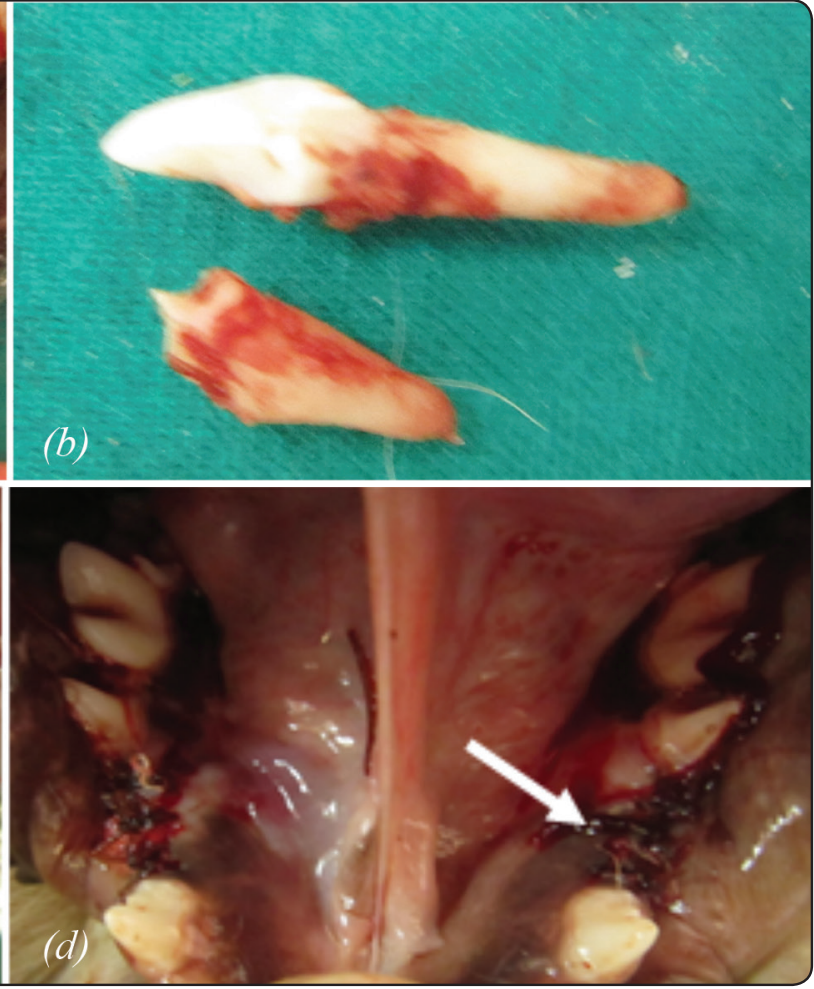

b: Extracted mandibular $3^{\text {rd }}$ premolar of dog

mposite scaffold inside teeth sockets (white arrow).

apatite crystal maturity $\left(\mathrm{CO}_{3} / \mathrm{PO}_{4}\right)$ and mineral to matrix ratio to suggest degree of calcification $\left(\mathrm{PO}_{4} /\right.$ Amide I). The data were analyzed by using base line technique to analyze the spectral vibration infrared according to Numata et al, 2008. Table 1 shows the selected parameters to assess bone quality. ${ }^{22}$ Spectra of hyaluronic acid alone and the biocomposite $(1 \mathrm{CH} / 2 \mathrm{MB})$ were done to investigate the chemical composition of both (Fig. 5).

\section{Statistical analysis:}

Values were presented as mean and standard deviation (SD). Data were explored for normality using Kolmogorov-Smirnov test of normality. The results of Kolmogorov-Smirnov test indicated that most of data were normally distributed (parametric data), so one way analysis of variance ANOVA test was used to compare between groups, followed by Tukey's post hoc test for pairwise comparisons. Paired t test was used to compare values at 3 and 6 weeks. 
The significance level was set at $P \leq 0.05$. Statistical analysis was performed with SPSS 16.0 (Statistical Package for Scientific Studies, SPSS, Inc., Chicago, IL, USA) for Windows.

TABLE (1) Bone healing parameters

\begin{tabular}{|c|c|c|c|}
\hline \multicolumn{2}{|l|}{ Parameter } & IR peaks assignment & Comments \\
\hline \multirow[b]{2}{*}{ Mineral Quality } & $\mathrm{PO}_{4}^{-3}$ & Relative area of Phosphate $\left(900-1200 \mathrm{~cm}^{-1}\right)$ & Mineral content \\
\hline & $\mathrm{CO}_{3} / \mathrm{PO}_{4}$ & $\begin{array}{l}\text { Relative area of sub-band at }\left(873 \mathrm{~cm}^{-1} / 1030\right. \\
\mathrm{cm}^{-1)}\end{array}$ & $\begin{array}{l}\text { Indicate degree of apatite crystal maturity } \\
\text { / the amount of carbonate substitution for } \\
\text { phosphate in the mineral crystals }\end{array}$ \\
\hline Matrix Quality & Amide I & Amide I $\left(1575-1720 \mathrm{~cm}^{-1}\right)$ & Protein contents in matrix \\
\hline $\begin{array}{l}\text { Mineral/Matrix } \\
\text { Ratio }\end{array}$ & $\begin{array}{l}\mathrm{PO}_{4}^{-3 /} \\
\text { Amide I }\end{array}$ & $\begin{array}{l}\text { Relative area of phosphate }(900-1200 \mathrm{~cm}-1) / \\
\text { amide I }(1575-1720 \mathrm{~cm}-1)\end{array}$ & Degree of calcification \\
\hline
\end{tabular}

\section{RESULTS}

\section{I- Regarding matrix quality (Collagen quality):}

The third week showed, higher mean value for the right side, followed by left side, with the least value in original bone. ANOVA test revealed that the difference between the three groups was statistically significant $(\mathrm{P}=0.011)$. Tukey's post hoc test showed no significant difference between right and left side (Table 2, Fig. 2 a). While, the sixth week showed, a higher mean value for the right, followed by left side, with the least value in original bone. ANOVA test revealed that the difference between the three groups was extremely significant $(\mathrm{P}=0.00)$. Tukey's post hoc test showed significant difference between each two groups, (Table 2, Fig. 2 b) In the right side, a higher mean value was recorded at 6 weeks, with significant difference $(\mathrm{P}=0.00)$. In the left side, a higher mean value was recorded at 6 weeks, with no significant difference $(\mathrm{P}=0.215)$, (Table 3 ) TABLE (2) Comparison between different groups regarding $\mathrm{PO}_{4} /$ Amide matrix quality collagen (ANOVA test)

\begin{tabular}{|c|c|c|c|c|c|c|c|c|c|c|}
\hline \multirow{2}{*}{ Time } & \multirow[t]{2}{*}{ Groups } & \multirow{2}{*}{ Mean } & \multirow{2}{*}{$\begin{array}{l}\text { Std. } \\
\text { Dev }\end{array}$} & \multirow{2}{*}{$\begin{array}{l}\text { Std. } \\
\text { Error }\end{array}$} & \multicolumn{2}{|c|}{$\begin{array}{l}95 \% \text { Confidence Interval } \\
\text { for Mean }\end{array}$} & \multirow{2}{*}{ Min } & \multirow{2}{*}{ Max } & \multirow{2}{*}{$\mathrm{F}$} & \multirow{2}{*}{$\mathrm{P}$} \\
\hline & & & & & $\begin{array}{l}\text { Lower } \\
\text { Bound }\end{array}$ & $\begin{array}{l}\text { Upper } \\
\text { Bound }\end{array}$ & & & & \\
\hline \multirow{3}{*}{$3 \mathrm{~W}$} & Right & $7.54^{\mathrm{a}}$ & .38 & .22 & 6.61 & 8.47 & 7.11 & 7.80 & 10.602 & $.011^{*}$ \\
\hline & Left & $7.42^{\mathrm{a}}$ & .32 & .18 & 6.63 & 8.21 & 7.10 & 7.74 & & \\
\hline & Original & $6.40^{\mathrm{b}}$ & .30 & .17 & 5.65 & 7.15 & 6.10 & 6.70 & & \\
\hline \multirow{3}{*}{$6 \mathrm{~W}$} & Right & $12.32^{\mathrm{a}}$ & .08 & .04 & 12.13 & 12.51 & 12.25 & 12.40 & 643.397 & $.000 *$ \\
\hline & Left & $7.74^{\mathrm{b}}$ & .20 & .11 & 7.25 & 8.23 & 7.52 & 7.90 & & \\
\hline & Original & $6.40^{c}$ & .30 & .17 & 5.65 & 7.15 & 6.10 & 6.70 & & \\
\hline
\end{tabular}

Significance level $p<0.05$, *significant Tukey's post hoc test: Within the same comparison, means sharing the same superscript letter are not significantly different 
TABLE (3) Comparison within the same group at 3 and 6 weeks regarding $\mathrm{PO}_{4} /$ Amide matrix quality (Paired $t$ test)

\begin{tabular}{|l|l|l|l|l|}
\hline & 3 weeks & 6 weeks & T & P \\
\hline Right & $7.54 \pm .38$ & $12.32 \pm .08$ & 21.32 & $0.00^{*}$ \\
\hline Left & $7.42 \pm .32$ & $7.74 \pm .20$ & 1.469 & $0.215 \mathrm{NS}$ \\
\hline
\end{tabular}

Significance level $p<0.05$, * significant, NS=non-significant

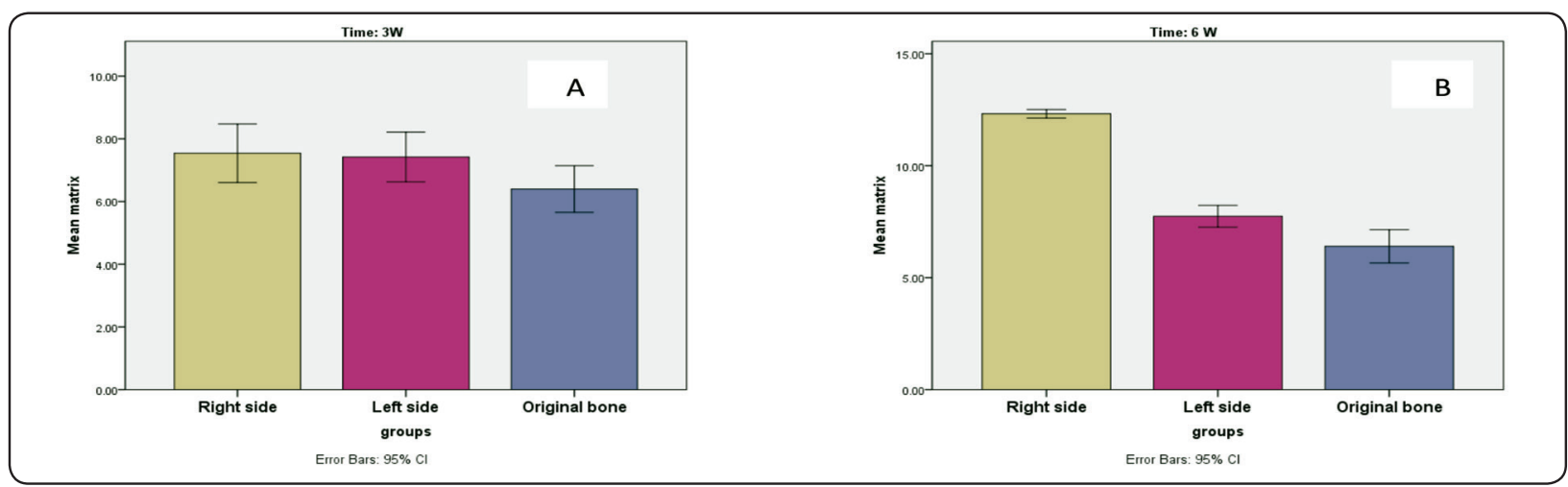

Fig. 2 (a, b): Bar chart showing mean $\mathrm{PO}_{4} /$ Amide matrix quality at 3 and 6weeks

II-Regarding mineral quality: (Degree of crystal maturity/ carbonate substitution)

The third week showed, higher mean value in original bone, followed right side, and left side, with the least value in control. ANOVA test revealed that the difference between the three groups was extremely significant $(\mathrm{P}=0.00)$. Tukey's post hoc test showed no significant difference between control and left side. (Table 4, Fig. 3a) The sixth week, a higher mean value was recorded in right side, followed by original bone, and then left side, with the least value in control. ANOVA test revealed that the difference between the three groups was extremely significant $(\mathrm{P}=0.00)$. Tukey's post hoc test showed no significant difference between control and left side, (Table 4, Fig. 3b) In the right side, a higher mean value was recorded at 6 weeks, with significant difference $(\mathrm{P}=0.0028)$, While in the left side, a higher mean value was recorded at 6 weeks, with no significant difference $(\mathrm{P}=0.288)$, (Table 5)

TABLE (4) Comparison between different groups regarding $\mathrm{Co}_{3} / \mathrm{Po}_{4}$ ratio degree of crystal maturity (ANOVA test)

\begin{tabular}{|c|c|c|c|c|c|c|c|c|c|c|}
\hline \multirow{2}{*}{ Time } & \multirow{2}{*}{ Group } & \multirow{2}{*}{ Mean } & \multirow{2}{*}{$\begin{array}{l}\text { Std. } \\
\text { Dev }\end{array}$} & \multirow{2}{*}{$\begin{array}{l}\text { Std. } \\
\text { Error }\end{array}$} & \multicolumn{2}{|c|}{ 95\% Confidence Interval for Mean } & \multirow{2}{*}{ Min } & \multirow{2}{*}{ Max } & \multirow{2}{*}{$\mathrm{F}$} & \multirow{2}{*}{$\mathrm{P}$} \\
\hline & & & & & Lower Bound & Upper Bound & & & & \\
\hline \multirow{4}{*}{$3 \mathrm{~W}$} & Right & $.071^{\mathrm{b}}$ & .003 & .002 & .064 & .078 & .069 & .074 & \multirow{4}{*}{55.03} & \multirow{4}{*}{$.000^{*}$} \\
\hline & Left & $.055^{\mathrm{c}}$ & .003 & .002 & .047 & .064 & .053 & .059 & & \\
\hline & \begin{tabular}{|l|} 
Original \\
\end{tabular} & $.082^{\mathrm{a}}$ & .005 & .003 & .069 & .095 & .078 & .088 & & \\
\hline & Control (empty) & $.047^{\mathrm{c}}$ & .003 & .001 & .041 & .054 & .045 & .050 & & \\
\hline \multirow{4}{*}{$6 \mathrm{~W}$} & Right & $.153^{\mathrm{a}}$ & .028 & .016 & .082 & .223 & .120 & .170 & \multirow{4}{*}{28.67} & \multirow{4}{*}{$.000 *$} \\
\hline & Left & $.058^{\mathrm{c}}$ & .003 & .002 & .051 & .066 & .055 & .061 & & \\
\hline & Original & $.082^{\mathrm{b}}$ & .005 & .003 & .069 & .095 & .078 & .088 & & \\
\hline & Control (empty) & $.055^{\mathrm{c}}$ & .005 & .003 & .043 & .067 & .050 & .060 & & \\
\hline
\end{tabular}

Significance level $p<0.05$, *significant

Tukey's post hoc test: Within the same comparison, means sharing the same superscript letter are not significantly different 
TABLE (5) Comparison within the same group at 3 and 6 weeks regarding $\mathrm{PO}_{4} /$ Amide matrix quality (Paired t test)

\begin{tabular}{|c|c|c|c|c|}
\hline & 3 weeks & 6 weeks & T & P \\
\hline Right & $.071 \pm .003$ & $.153 \pm .028$ & $\mathbf{6 . 5 3 2}$ & $\mathbf{0 . 0 0 2 8} *$ \\
\hline Left & $.055 \pm .003$ & $.058 \pm .003$ & $\mathbf{1 . 2 2 4 7}$ & $\mathbf{0 . 2 8 7 9 N S}$ \\
\hline
\end{tabular}

Significance level $p<0.05$, * significant, NS=non-significant

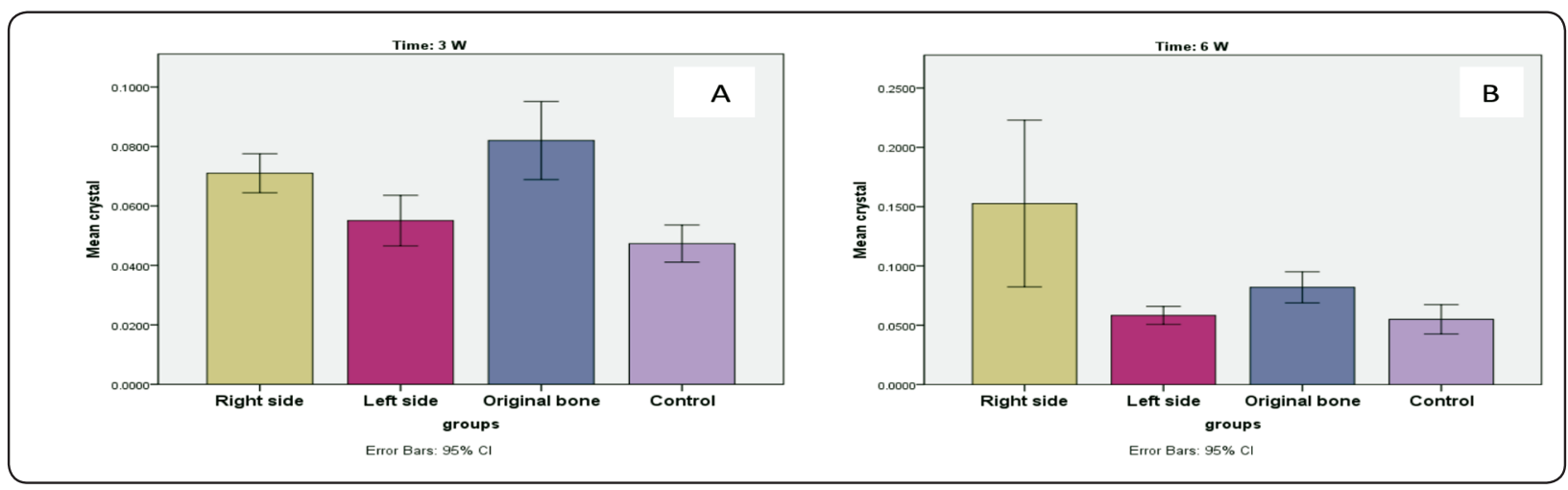

Fig. 3 (a, b): Bar chart showing mean $\mathrm{Co}_{3} / \mathrm{Po}_{4}$ ratio degree of crystal maturity at 3 and 6 weeks

\section{III-Regarding $\mathrm{PO}_{4} /$ Amide: Degree of calcification}

The third week showed, higher mean value in original bone, followed by left side, with the least value in right side. ANOVA test revealed that the difference between the three groups was extremely significant $(\mathrm{P}=0.00)$. Tukey's post hoc test showed significant difference between each two groups (Table 6, Fig. 4a). The sixth week showed, higher mean value in original bone, followed by left side, with the least value in right side. ANOVA test revealed that the difference between the three groups was extremely significant $(\mathrm{P}=0.00)$. Tukey's post hoc test showed a significant difference between each two groups, (Table 6, Fig. 4b) In the right side, a higher mean value was recorded at 6 weeks, with no significant difference $(\mathrm{p}=0.617)$ In the left side, a higher mean value was recorded at 3 weeks, with no significant difference $(\mathrm{p}=0.79)$, (Table7)

TABLE (6) Comparison between different groups regarding $\mathrm{PO}_{4} /$ Amide degree of calcification (ANOVA test)

\begin{tabular}{|c|c|c|c|c|c|c|c|c|c|c|}
\hline \multirow{2}{*}{ Time } & \multirow{2}{*}{ Groups } & \multirow{2}{*}{ Mean } & \multirow{2}{*}{$\begin{array}{l}\text { Std. } \\
\text { Dev }\end{array}$} & \multirow{2}{*}{$\begin{array}{l}\text { Std. } \\
\text { Error }\end{array}$} & \multicolumn{2}{|c|}{$\begin{array}{l}\text { 95\% Confidence Interval for } \\
\text { Mean }\end{array}$} & \multirow{2}{*}{ Min } & \multirow{2}{*}{ Max } & \multirow{2}{*}{$\mathrm{F}$} & \multirow{2}{*}{$\mathrm{P}$} \\
\hline & & & & & Lower Bound & Upper Bound & & & & \\
\hline \multirow{3}{*}{$3 \mathrm{~W}$} & Right & .64 & .16 & .09 & .23 & 1.05 & .52 & .83 & \multirow{3}{*}{301.587} & \multirow{3}{*}{$.000^{*}$} \\
\hline & Left & $1.45^{\mathrm{b}}$ & .15 & .08 & 1.09 & 1.81 & 1.31 & 1.60 & & \\
\hline & Original & $3.71^{\mathrm{a}}$ & .17 & .10 & 3.30 & 4.12 & 3.60 & 3.90 & & \\
\hline \multirow{3}{*}{$6 \mathrm{~W}$} & Right & $.69^{c}$ & .01 & .00 & .67 & .71 & .68 & .70 & \multirow{3}{*}{685.186} & \multirow{3}{*}{$.000^{*}$} \\
\hline & Left & $1.22^{\mathrm{b}}$ & .08 & .05 & 1.01 & 1.42 & 1.14 & 1.30 & & \\
\hline & Original & $3.71^{\mathrm{a}}$ & .17 & .10 & 3.30 & 4.12 & 3.60 & 3.90 & & \\
\hline
\end{tabular}

Significance level $p<0.05$, *significant

Tukey's post hoc test: Within the same comparison, means sharing the same superscript letter are not significantly different 
TABLE (7) Comparison within the same group at 3 and 6 weeks regarding $\mathrm{PO}_{4} /$ Amide degree of calcification (Paired $t$ test)

\begin{tabular}{|l|l|l|l|l|}
\hline & 3 weeks & 6 weeks & T & P \\
\hline Right & $.64 \pm .16$ & $.69 \pm .01$ & 0.5402 & 0.6177 NS \\
\hline Left & $1.45 \pm .15$ & $1.22 \pm .08$ & 2.34 & 0.079 NS \\
\hline
\end{tabular}

Significance level $p<0.05$, NS=non-significant

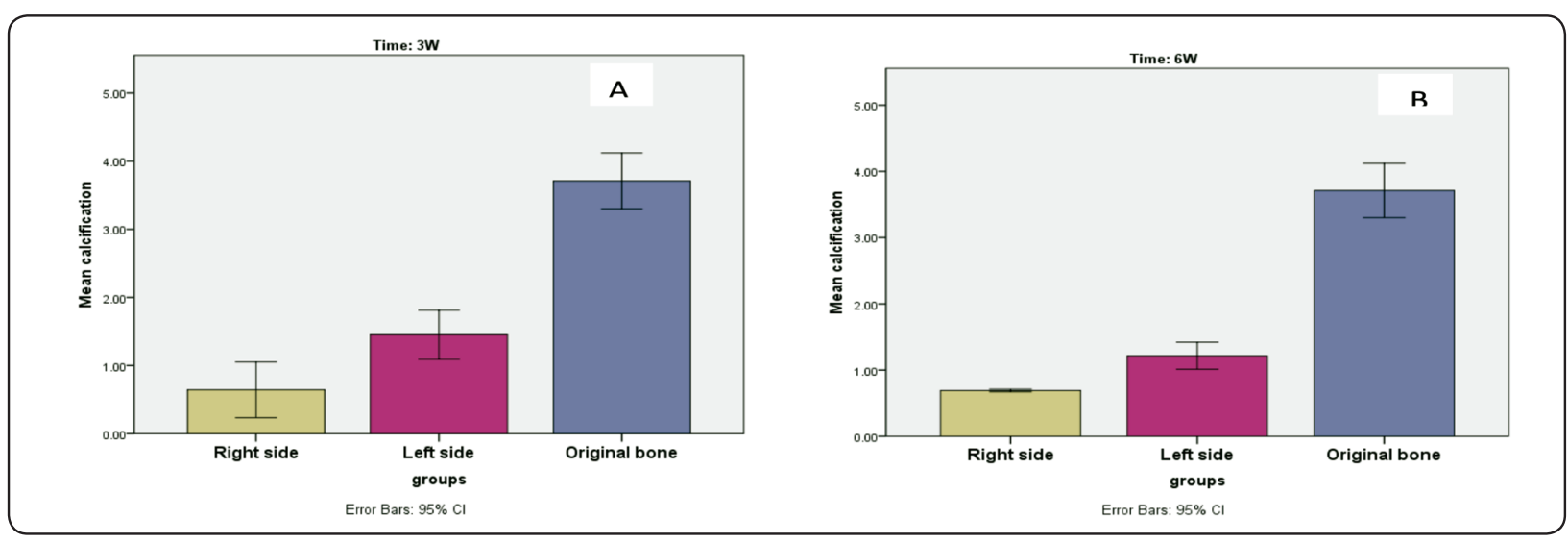

Fig. 4 (a, b): Bar chart showing mean $\mathrm{PO}_{4} /$ Amide degree of calcification at 3 weeks

VI- Chemical composition of hyaluronic acid (HLA) and chitosan melted bioactive glass biocomposite $(1 \mathrm{CH} / 2 \mathrm{MB})$ each alone.

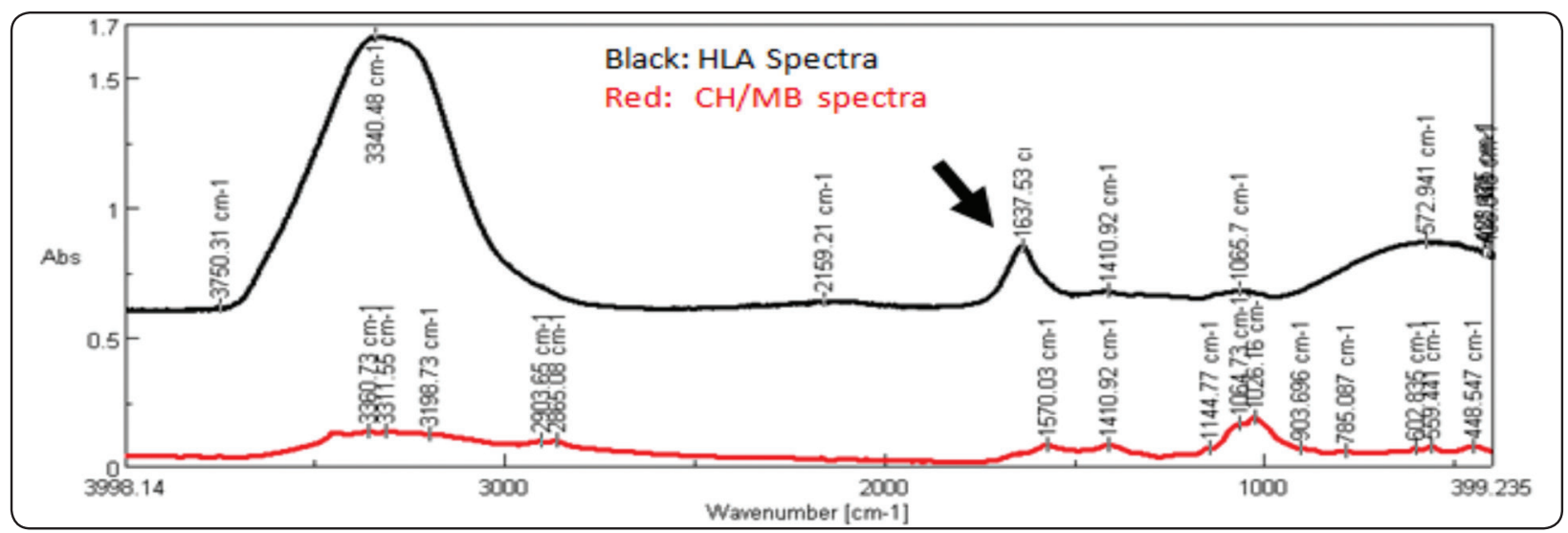

Fig. 5: Spectral bands for hyaluronic acid (Black) and chitosan melted bioactive glass biocomposite (Red). 


\section{DISCUSSION}

The biocompatibility of chitosan bioactive glass bio-composite soaked in the commercially available $0.2 \%$ hyaluronic acid (CH-MB-HLA) was confirmed as there no abnormal clinical inflammatory response along the study periods. Trabecular bone structure is complex, and also its numerical quantification. The current study choose a non-invasive conservative method to study different variables concerning bone formation.

Chitosan $(\mathrm{CH})$ and hyaluronic acid (HLA) are similar in the chemical structure, they have wound healing properties. The chitosan acts as stimulant for HLA release. ${ }^{12}$ Chitosan is a positively charged polysaccharide. While, HLA is a negatively charged molecules. Therefore, chitosan can electrostatically interact with HLA. ${ }^{21}$ Muzzarelli et al. described $\mathrm{CH}$ has the capacity to promote more HLA synthesis. ${ }^{10}$

The Fourier transform infrared spectroscopy (FTIR) analyses confirm the presence of carbonate bands on the surface of chitosan / bioactive glass composites which is responsible for rapid formation of crystallized apatite layer (more carbonate containing), in comparison with pure bioactive glass. ${ }^{16}$ The sample composition chosen was (1 chitosan (CH): 2 melted bioactive glass (MB)). The interaction between such bioaglass and chitosan chains result in bone bonding and controlled bioglass degradation. ${ }^{16}$

Exogenous high-molecular weight (HMW)hyaluronic acid was used due to increased adherence (high viscosity in gel form), and antibacterial activity. Low-molecular weight HLA does not gel like the HMW-Hyaluronic acid. Besides, the powder form is thin and difficult to handle compared to the regular high molecular hyaluronic acid. Locally applied HMW-Hyaluronic acid may have the advantage of retaining itself and growth factors within the tissue to which it was applied. The higher the MW was, the higher rate of bone formation. ${ }^{14,17,23}$ Many researchers evaluated HLA effects on bone healing. It increased the expressions of bone matrix components (Alkaline phosphatase ALP, and Osteopontain OCN). 17,23 Moreover, Tumor necrosis factor-alpha (TNF- $\alpha$ ) play a vital role in the healing cascade, as the osteoblasts number expressed TNF- $\alpha$ was higher in 2 weeks in HLA treated group than control one, but in 4 weeks showed a markedly decrease in number. ${ }^{25}$

The current study indicated long term effects and suspected sustain release of HLA, as the mean values for collagen content at 6 weeks were highly significant in HLA treated groups compared to HLA free groups at the same interval. While at 3 weeks group there is no significance between HLA treated and $\mathrm{CH} / \mathrm{MB}$ group. Regarding, mean values of carbonated hydroxyapatite at 6 Weeks showed higher values in HLA group with significant results. The spectral bands of HLA showed more collagen content than the biocomposite (Fig.5) .

Salt et al demonstrated that HLA-tested specimens showed more orderly oriented strong collagen fibers, regarding the flexor tendon wounds in rabbits. ${ }^{13}$ Our study confirmed high collagen content in HLA treated groups by means 7.54 at 3 weeks and 12.32 at 6 weeks compered to non-treated sites that was 7.42 at $3 \mathrm{w}$ and 7.74 at 6 weeks. While, crystal maturation in HLA treated groups was 0.71 at 3 weeks and 0.153 at $6 \mathrm{w}$ compered to non-treated sites that was 0.055 at $3 \mathrm{w}$ and 0.058 at 6 weeks with significant increase.

In rat clavarial defects, 1\% HLA gel showed non- significant results when used alone. While, using collagen sponge soaked in $1 \%$ HLA result in more effective bone healing. ${ }^{24}$ Aslan et al. (2006) concluded that HLA needs a scaffold to improve the rat of bone formation. However, Mendes et al. (2008), concluded the effectiveness of such concentrations in rat maxillary molar fresh extraction sockets, as regard number bone trabeculae at $1 \& 3$ weeks and number of blood vessels at first week. Furthermore, HLA increases the expression of growth factor BMP-2 and protein of bone matrix osteopontin..$^{5,15,24-26}$. HLA may act as a biomimetic 
scaffold for other molecules, such as BMP-2 and TGF- $\beta .{ }^{13,14}$ Current study revealed more collagen and crystal maturity in HLA treated sites especially at 6 weeks as mentioned before.

Alcantara et al, reported high bone formation in lower first premolar human sockets filled with HLA at 30 days, whereas at 90 days there was no difference between HLA and control groups. Also the alveolar bone dimensions showed no significant difference in the same study. It was concluded that HLA affected the early stages of bone healing 5,24-26 For this reason the current study evaluated periods of 3 weeks and 6 weeks (early stages of bone healing).

\section{CONCLUSIONS}

Within the limitation of this study, hyaluronic acid could enhance bone regeneration by sustaining its release until 6 weeks when an osteocoductive scaffold soaked in $0.2 \%$ HLA.

\section{RECOMMENDATIONS}

Increased HLA concentration should be used, and the suspected sustain release should be confirmed on further studies.

\section{REFERENCES}

1. Tomlin EM, Nelson SJ, Rossmann JA. Ridge Preservation for Implant Therapy: a Review of the Literature. The Open Dentistry Journal. 2014; 8: 66-76.

2. Hong JY, Lee JS, Pang EK, Jung UW, and Choi SH: Impact of different synthetic bone fillers on healing of extraction sockets: an experimental study in dogs. Clin. Oral Impl. Res. 25, 2014, e30-e37doi: 10.1111/clr.12041

3. Jazayeri HE, Fahmy MD, Razavi M, Stein BE, Nowman A, Masri R, and Tayeb L. Dental Applications of NaturalOrigin Polymers in: Hard and Soft Tissue Engineering. Journal of Prosthodontics, Vol. 25, 6 (August 2016): 510-517.

4. Shi C, Uan Z, Han F, Zhu C, Li B: Polymeric biomaterials for bone regeneration. Ann Joint 2016; 1:27

5. Alcòntara CEP, Castro MAA, Noronha MS, MartinsJunior PA, Caliari MV, Mesquita RA, Ferreira AJ. Hyaluronic acid accelerates bone repair on human dental sockets: a randomized triple-blind clinical trial. Braz. Oral Res.2018; 32:e84

6. Kim CK, Araujo M, Linder E, Wennstro“MJ \& Lindhe J: The influence of Bio-Oss collagen on the healing of an extraction socket: An experimental study in the dog. Inter J of Perio Rest Dent. 2008; 28, 123-35.

7. Manuela G. Neuman, Radu M. Nanau, Loida OruñaSanchez, Gabriel Coto. Hyaluronic Acid and Wound Healing. J Pharm Pharm. 2015; 18(1): 53-60.

8. Neuman MG, Nanau RM, Oruña L, Coto G. In vitro antiinflammatory effects of hyaluronic

9. E. Aguado, F. Pascaretti-Grizon, C. Gaudin-Audrain, E. Goyenvalle, and D. Chappard, " $\beta$-TCP granules mixed with reticulated hyaluronic acid induce an increase in bone apposition," Biomedical Materials, vol. 9, no. 1, Article ID 015001, 2014

10. Chang HH, Wang YL, ChiangYC, Chen YL, ChuangYH, Tsai SJ, Heish KH, Lin FH, Lin CP: A Novel ChitosancPGA Polyelectrolyte Complex Hydrogel Promotes Early New Bone Formation in the Alveolar Socket Following Tooth Extraction. March 2014 | Volume 9 | Issue 3 | e92362

11. Radhi IH, Al-Ghaban NM. Evaluation the effect of hyaluronic acid on bone healing process in rabbits (Immunohistochemical study for TGF- $\beta$ ). J Bagh Coll Dentistry. 2015; 27(1):111-116. 5. Leach JB, Bivens KA, Collins CN, and Schmidt CE.

12. Chang YL, June-Lo Y, Wei-Feng S, Chih-Huang Y, TongLin C, Hsin-Fan $\mathrm{K}$, and Ming-Huang H. Bone healing improvements using hyaluronic acid and hydroxyapatite/ beta-tricalcium phosphate in combination: an animal study. BioMed Research International volume 2016.

13. Nashar A,Ahmed E, Khedder Y, and Al-Katib O.Evaluating the effect of hyaluronic acid on bone healing process: An experimental study in rabbits. European Journal of Pharmaceutical and medical research 2017,4(1),98-101

14. Yazan M, Kocyigit ID, Atil F, Tekin U, Gonen Z B, Onder ME. Effect of hyaluronic acid on the osseointegration of dntal implants. British Journal of Oral And Maxillifacial Surgery

15. Aslan M, Simsek G and Dayi E: The Effect of Hyaluronic Acid-supplemented Bone Graft in Bone Healing: Experimental Study in Rabbits. J Biomat. APP Volume 20- January 2006

16. Hammad, H. G. H. ; Mostafa, Amany A. ; Hashem, A. M. ; Oudadesse, H. ; Badr, N. A. ; Habib, S.I. ; Mabrouk, Mostafa ; Mahmoud, A.A. ; El-Gohary , M.I.: Bioactivity 
and Drug Delivering Ability of a Chitosan/46S6 Melted Bioactive Glass Biocomposite Scaffold: Interceram 62 [6]: 444-452, 2013 [International publication]. Ceramic review · January 2013.

17. Sasaki T, Watanabe C. (Stimulation of osteoinduction in bone wound healing by high-molecular hyaluronic acid). Bone, 1995; 16: 9-15.

18. Oudaesse, H., Bui, X.V., Yann, L.: Chitosan Effects on Bioactive Glass for Application as Biocopmosite. Biomaterial. Int J. Biolog. And Biomed. Eng. 5 (2011)

19. Jonathan M, Bioactive Glass in Tissue Engineering: Progress and Challenges. Adv Tissue Eng Regen Med Open Access. 2016;1(1):3-4

20. Almança Lopes CDC, Oliveira Limirio PHJ, and Paula Dechichi VRN: Fourier transform infrared spectroscopy (FTIR) application chemical characterization of enamel, dentin and bone. Journal Applied Spectroscopy Reviews. 2018; 53(9): 747-69.

21. Chen, W.Y.J., Abatangelo, G. Functions of hyaluronan in wound repair. Wound Repair Regen 1999; 7: 2, 79-89

22. Numata Y, Nakada H, Sakae T, Kimura-Suda H, Le Geros R, Kobayashi K, Makimura M. Qualitative study of the new bone formation surrounding the Ti-implant by FTIR and polarizing microscope. $\mathrm{J}$ of Hard Tissue Biology: 17(3); 131-140, 2008.

23. Zhao N, Wang W, Qin L, Guo Z, and Li D, "Effect of molecular weight and concentration of hyaluronan on cell proliferation and osteogenic differentiation in vitro," Biochemical and Biophysical Research Communications, vol. 465, no. 3, pp. 569-574, 2015. View at Publisher · View at Google Scholar. View at Scopus

24. De Brito Bezerra B, Brazão MAM, de Campos MLG, Casati MZ, Sallum EA, Sallum AW. Association of hyaluronic acid with a collagen scaffold may improve bone healing in critical size bone defects. Clin. Oral Impl. Res. 23,2012,938-942 doi: 10.1111/j.1600-0501.2011.02234.x

25. Mohammad MH\& Al-Ghaban NMH: The effects of hyaluronic acid on bone-implant interface in rabbits (immunohistochemical study for TNF- $\alpha$ ). IJABR, VOL.7 (4) 2017: 733-738

26. Mendes RM, Silva GA, Lima MF, Calliari MV, Almeida AP, Alves JB et al. Sodium hyaluronate accelerates the healing process in tooth sockets of rats. Arch Oral Biol. 2008 Dec; 53(12):1155-1162. https://doi.org/10.1016/j. archoralbio.2008.07.001 